\title{
Parâmetros da fermentação ruminal e concentração de derivados de purina de vacas em lactação alimentadas com castanha de caju
}

\author{
[Ruminal fermentative parameters and concentration of purine derivatives in lactating \\ dairy cows fed cashew nut] \\ P.G. Pimentel ${ }^{1}$, R.B. Reis ${ }^{2 *}$, L.A. Leite ${ }^{2}$, W.E. Campos $^{3}$, J.N.M. Neiva ${ }^{4}$, \\ H.M. Saturnino ${ }^{2}$, S.G. Coelho ${ }^{2}$ \\ ${ }^{1}$ Universidade Federal do Ceará - Fortaleza, Ce \\ ${ }^{2}$ Escola de Veterinária - UFMG - Belo Horizonte, MG \\ ${ }^{3}$ Fiscal Federal Agropecuário do MAPA - Brasília, DF \\ ${ }^{4}$ Escola de Medicina Veterinária e Zootecnia - UFT - Araguaína, TO \\ RESUMO
}

\begin{abstract}
Avaliaram-se os parâmetros de fermentação ruminal e a concentração de derivados de purinas na urina de vacas leiteiras alimentadas com teores crescentes de castanha de caju na dieta. Foram utilizadas oito vacas Holandesas multíparas, sendo quatro fistuladas no rúmen, com produção média de $28 \pm 4 \mathrm{~kg}$ de leite/dia. O delineamento experimental adotado foi o quadrado latino $4 \times 4$, com parcelas subdivididas para os parâmetros ruminais e duplo para determinação dos derivados de purina. Os tratamentos avaliados consistiram na inclusão de $0 ; 8 ; 16$ e $24 \%$ de castanha de caju moída na porção concentrada da dieta. O comportamento do $\mathrm{pH}$ ruminal foi semelhante entre as dietas avaliadas segundo os tempos após alimentação. A concentração média de nitrogênio amoniacal foi $12,70 \mathrm{mg} / 100 \mathrm{~mL}$ de líquido ruminal. Os valores médios de acetato e butirato apresentaram padrão linear de resposta, contudo a relação acetato:propionato não foi alterada pela adição do coproduto. As excreções de derivados de purina na urina não variaram significativamente $(\mathrm{P}>0,05)$ com a adição de castanha de caju. A inclusão de castanha de caju não afetou os parâmetros de fermentação ruminal nem as concentrações de derivados de purinas; dessa forma, pode ser recomendada como alternativa potencial na alimentação de vacas leiteiras em lactação.
\end{abstract}

Palavras-chave: ácido úrico, alantoína, coproduto, lipídeos, $\mathrm{pH}$

\begin{abstract}
The parameters of rumen fermentation and the concentration of purine derivatives in the urine of dairy cows fed with increasing levels of cashew nut in the diet were evaluated. Eight multiparous holstein cows were used, being four rumen cannulated, with average production of $28 \pm 4 \mathrm{~kg}$ of milk/day. The experimental design adopted was a $4 \times 4$ Latin square with split plots for the ruminal parameters and double for the determination of purine derivatives. The treatments consisted of the inclusion of $0 ; 8 ; 16$ and $24 \%$ of cashew nut in the concentrate portion of the diet. The behavior of the ruminal pH was similar between the evaluated diets according to the time after feeding. The average concentration of ammonia nitrogen was $12.70 \mathrm{mg} / 100 \mathrm{~mL}$ of rumen fluid. The average values of acetate and butyrate showed a linear response, but the acetate:propionate ratio was not altered by the addition of the coproduct. The excretions of purine derivatives in urine did not differ significantly $(P>0.05)$ with the addition of cashew nut. The inclusion of cashew nut did not affect ruminal fermentation parameters neither the concentrations of purine derivatives, so it can be recommended as a potential alternative for feeding dairy cows.
\end{abstract}

Keywords: allantoin, coproduct, lipids, $\mathrm{pH}$, uric acid

Recebido em 11 de março de 2011

Aceito em 15 de maio de 2012

*Autor para correspondência (corresponding author)

E-mail: rbreis@vet.ufmg.br

Apoio financeiro: Banco do Nordeste do Brasil 


\section{INTRODUÇÃO}

A alimentação de vacas leiteiras é sempre primeiramente relacionada aos custos de produção, de forma plenamente justificada, já que esta variável representa mais da metade do custo operacional na produção de leite. A importância do arraçoamento de bovinos de leite implica diretamente na eficiência produtiva, na qualidade do leite, na saúde, na reprodução e no bem-estar dos animais. A utilização racional dos resíduos agroindustriais tem consistido em alternativa promissora para diminuição dos custos e manutenção dos níveis de produção de vacas leiteiras (Pimentel et al., 2007).

A atividade da cajucultura no Nordeste do Brasil origina coprodutos passíveis de utilização na alimentação animal, podendo constituir opção viável para melhoria do manejo nutricional do rebanho leiteiro. Neste contexto, os resíduos resultantes da industrialização do caju poderão representar uma alternativa para a redução dos custos de produção na atividade leiteira, sobretudo na referida região, onde esta cultura é plenamente adaptada e desenvolvida. O coproduto da castanha de caju destaca-se devido a sua composição química, apresentando-se como alimento de bom valor nutritivo e baixo custo para a alimentação de vacas leiteiras (Pimentel et al., 2007). A adição de castanha de caju como fonte de lipídeos possibilita o incremento energético da dieta, favorece a relação volumoso:concentrado, reduz o risco de acidose ruminal e permite melhor desempenho produtivo e reprodutivo das vacas leiteiras.

Segundo Oliveira et al. (2009), o interesse em melhorar a eficiência de utilização de nutrientes pelos ruminantes tem incentivado estudos para avaliação de alimentos utilizando dietas balanceadas e considerando as múltiplas interrelações dos microrganismos ruminais $x$ hospedeiro.

Considerando-se os parâmetros de fermentação ruminal, o decréscimo no $\mathrm{pH}$ do rúmen pode influenciar negativamente o consumo de matéria seca, a motilidade ruminal, a degradação da fração fibrosa e a produção microbiana, influenciando $\mathrm{o}$ adequado funcionamento do rúmen e, consequentemente, a saúde do animal (Van Soest, 1994). O excesso de nitrogênio não proteico ou de proteína fermentada é convertido em amônia, a qual é absorvida, convertida em ureia pelo fígado e excretada pela urina. Contudo, o fornecimento de energia pode, pelo aumento nos requisitos dos microrganismos para a síntese de proteína microbiana, melhorar o aproveitamento da amônia (Van Soest, 1994). Os ácidos graxos voláteis (AGV) são os principais produtos finais da fermentação ruminal dos carboidratos realizada pelos microrganismos, sendo os mais importantes o acetato, o propionato e o butirato (Van Soest, 1994). Os produtos da fermentação ruminal constituem importantes parâmetros na avaliação das dietas fornecidas aos animais em produção.

A fonte e a porcentagem de inclusão de lipídeo à dieta podem influenciar os parâmetros fermentativos do rúmen. No entanto, a maioria das pesquisas ressalta que a adição de lipídeos exerce pouco ou nenhum efeito sobre as atividades dos microrganismos $\mathrm{e}$ as demais características do ambiente ruminal, quando se considera o limite superior de fornecimento de $7 \%$ da matéria seca total da dieta (Maia et al., 2006; Vargas et al., 2002).

O objetivo deste estudo foi avaliar os parâmetros de fermentação ruminal e a concentração de derivados de purinas na urina de vacas leiteiras alimentadas com teores crescentes de castanha de caju na dieta.

\section{MATERIAL E MÉTODOS}

Para a determinação dos parâmetros ruminais, foram utilizadas quatro vacas Holandesas multíparas, fistuladas no rúmen, entre 50 e 74 dias pós-parto, com produção média de $28 \pm 4 \mathrm{~kg}$ de leite/dia, com peso corporal médio de $555 \mathrm{~kg}$, dispostas em um delineamento quadrado latino $4 \times 4$ com parcelas subdivididas. A pesquisa teve duração de 84 dias, divididos em quatro períodos de 21 dias, sendo 14 dias de adaptação e sete dias de coleta de dados. Os animais permaneceram confinados e individualizados em instalações do tipo tie stall, com livre acesso à água. Os tratamentos avaliados consistiram na inclusão de $0 ; 8 ; 16$ e $24 \%$ de castanha de caju moída na porção concentrada da dieta (Tab. 1).

As dietas foram balanceadas para atender às exigências nutricionais das vacas de acordo com o Nutrient... (2001), sendo fornecidas duas vezes ao dia, após as ordenhas, às sete e 17 horas, 
permitindo sobras de $10 \%$. A silagem de milho foi utilizada como alimento volumoso único e as dietas foram formuladas para serem isoproteicas. A relação volumoso:concentrado utilizada foi de 50:50.

Os teores de matéria seca (MS), cinzas, proteína bruta $(\mathrm{PB})$, extrato etéreo $(\mathrm{EE})$, cálcio $(\mathrm{Ca})$ e fósforo $(\mathrm{P})$ foram determinados segundo a AOAC (1995). As análises de fibra em detergente neutro (FDN) e fibra em detergente ácido (FDA) foram realizadas de acordo com Van Soest et al. (1991). A porcentagem de carboidratos não fibrosos (CNF) nas dietas foi calculada segundo a equação proposta pelo Nutrient... (2001): \%CNF $=100-(\% \mathrm{~PB}+$ $\%$ FDN $+\%$ EE $+\%$ Cinzas), e os teores de carboidratos totais (CHOT) obtidos conforme Sniffen et al. (1992): \%CHOT = $100-(\% \mathrm{~PB}+$ $\% \mathrm{EE}+\%$ Cinzas).

Tabela 1. Composição químico-bromatológica da silagem de milho, da castanha de caju (CC) e dos concentrados experimentais

\begin{tabular}{lcccccc}
\hline \multirow{2}{*}{$\begin{array}{l}\text { Nutriente } \\
(\% \mathrm{MS})^{1}\end{array}$} & $\begin{array}{c}\text { Silagem de } \\
\text { milho }\end{array}$ & $\begin{array}{c}\text { Castanha de } \\
\text { caju }\end{array}$ & \multicolumn{5}{c}{ Concentrado $^{2}$} \\
\cline { 4 - 7 } MS & 39,64 & 94,05 & 90,48 & 90,02 & 91,24 & 90,57 \\
PB & 8,64 & 24,45 & 26,75 & 25,52 & 25,70 & 25,29 \\
EE & 5,13 & 44,09 & 3,59 & 8,20 & 11,68 & 15,58 \\
CHOT & 82,83 & 25,34 & 61,24 & 57,86 & 55,16 & 50,91 \\
CNF & 32,27 & 8,46 & 34,64 & 35,17 & 31,56 & 28,94 \\
FDN & 50,56 & 16,88 & 26,59 & 22,68 & 23,66 & 21,97 \\
FDA & 29,15 & 9,38 & 13,73 & 14,07 & 15,36 & 15,02 \\
Cinzas & 3,40 & 6,12 & 8,43 & 8,43 & 7,40 & 8,22 \\
Ca & 0,37 & 0,42 & 1,52 & 1,47 & 1,44 & 1,46 \\
P & 0,18 & 0,81 & 0,73 & 0,57 & 0,65 & 0,72 \\
\hline
\end{tabular}

${ }^{1}$ MS: matéria seca; PB: Proteína bruta; EE: Extrato etéreo; NDT: Nutrientes digestíveis totais; CHOT: Carboidratos totais; CNF: Carboidratos não fibrosos; FDN: Fibra em detergente neutro; FDA: Fibra em detergente ácido; Ca: Cálcio; P: Fósforo. ${ }^{2}$ C0: Sem CC; C8: 8\% de CC; C16: $16 \%$ de CC; C24: 24\% de CC.

Os teores de FDN e FDA de todas as dietas experimentais situaram-se acima do mínimo de 28 e 21\%, respectivamente, segundo o recomendado pelo Nutrient... (2001); (Tab. 2). A castanha de caju contribuiu com, aproximadamente, 46,0; 61,8 e $67,7 \%$ do total de extrato etéreo presente nos concentrados quando os níveis de inclusão deste ingrediente foram de $8 ; 16$ e $24 \%$, respectivamente.

As amostras de fluido ruminal foram coletadas manualmente, via fístula ruminal, e filtradas em camada dupla de gaze no $15^{\circ}$ dia de cada período experimental. Os tempos de coleta foram imediatamente antes da alimentação (zero hora) e às duas, três, seis, nove e 12 horas após a alimentação da tarde e da manhã, totalizando 24 horas. Foi realizada leitura imediata do $\mathrm{pH}$ do líquido ruminal utilizando-se um potenciômetro digital de bolso. Amostras de 50mL de líquido ruminal foram acidificadas em $1 \mathrm{~mL}$ de ácido sulfúrico a $50 \%$ e armazenadas a $-20^{\circ} \mathrm{C}$ para futuras análises de $\mathrm{N}-\mathrm{NH}_{3}$. Outra alíquota de
$4 \mathrm{~mL}$ foi conservada em $1 \mathrm{~mL}$ de ácido metafosfórico $(25 \%)$, armazenada a $-20^{\circ} \mathrm{C}$, para posteriores análises de AGV.

Ao final do experimento, as amostras foram descongeladas à temperatura ambiente, sendo a concentração de $\mathrm{N}_{-} \mathrm{NH}_{3}$ obtida pela destilação com óxido de magnésio, utilizando-se ácido bórico como solução receptora e ácido clorídrico $0,01 \mathrm{~N}$ na titulação. A concentração de ácidos graxos voláteis, medida após a centrifugação do líquido ruminal em centrífuga Sorvall RC-5B Refrigerated Superspeed Centrifugue (Du Pont Instruments $^{\circledR}$ ) a $5000 \mathrm{~g}$ por 20 minutos a $4^{\circ} \mathrm{C}$, foi quantificada com o uso de cromatógrafo de fase gasosa, SHIMADZU ${ }^{\circledR}$, modelo GC-17A, com autoinjetor Shimadzu CBM-101, acoplado a um microcomputador Pentium 100 com software Class - GC10 versão 1.61. Os AGV foram separados com uma coluna NukolTM capilar de sílica fundida $(10 \mathrm{~m} \times 0,25 \mathrm{~mm} \times 0,25 \mathrm{~mm}$ Film Thickness, Sulpelco, Inc., Bellefonte, PA). 
Tabela 2. Composição centesimal e químico-bromatológica das dietas experimentais com diferentes proporções de castanha de caju (CC)

\begin{tabular}{|c|c|c|c|c|}
\hline \multirow{2}{*}{ Ingrediente (\%MS) } & \multicolumn{4}{|c|}{ Dieta $^{1}$} \\
\hline & 0 & 8 & 16 & 24 \\
\hline Silagem de milho & 50,00 & 50,00 & 50,00 & 50,00 \\
\hline Castanha de caju & 0,00 & 3,76 & 7,53 & 11,29 \\
\hline Milho, grão moído & 18,15 & 14,58 & 13,13 & 12,44 \\
\hline Farelo de soja & 18,09 & 16,55 & 14,68 & 12,85 \\
\hline Polpa cítrica & 11,33 & 12,95 & 12,39 & 10,82 \\
\hline Ureia & 0,32 & 0,32 & 0,32 & 0,32 \\
\hline Premix min.-vit. ${ }^{2}$ & 0,64 & 0,64 & 0,65 & 0,65 \\
\hline Cloreto de sódio & 0,27 & 0,27 & 0,27 & 0,27 \\
\hline Calcário & 0,32 & 0,32 & 0,27 & 0,43 \\
\hline Bicarbonato de sódio & 0,27 & 0,27 & 0,27 & 0,27 \\
\hline \multicolumn{5}{|l|}{ Nutriente $(\% M S)$} \\
\hline Matéria seca & 50,18 & 51,25 & 50,02 & 49,40 \\
\hline Proteína bruta & 15,77 & 16,22 & 15,36 & 14,59 \\
\hline Extrato etéreo & 3,16 & 4,60 & 6,89 & 7,31 \\
\hline Carboidratos totais & 75,15 & 73,92 & 71,93 & 71,85 \\
\hline Carboidratos não fibrosos & 29,64 & 28,07 & 27,63 & 27,82 \\
\hline Fibra em detergente neutro & 45,51 & 45,85 & 44,30 & 44,03 \\
\hline Fibra em detergente ácido & 29,87 & 28,07 & 27,63 & 27,82 \\
\hline Cinzas & 5,92 & 5,26 & 5,82 & 6,25 \\
\hline Cálcio & 0,74 & 0,78 & 0,78 & 0,72 \\
\hline Fósforo & 030 & 034 & 0.34 & 031 \\
\hline
\end{tabular}

0: dieta sem CC; 8: dieta com 8\% de CC na porção concentrada; 16: dieta com 16\% de CC na porção concentrada; 24: dieta com $24 \%$ de CC na porção concentrada.

${ }^{2}$ Composição por kg: Ca: 21,0\%; P: 16,0\%; S: 2,1\%; Fe: 2000ppm; Cu: 2000ppm; Zn: 5000ppm; Mn: 1600ppm; I: 160ppm; Se: 30ppm; Co: 185ppm; F(máx): 1600ppm.

Para determinação das concentrações de creatinina, alantoína e ácido úrico, foram utilizadas oito vacas Holandesas multíparas, entre 50 e 74 dias pós-parto, com produção média de $28 \pm 4 \mathrm{~kg}$ de leite/dia, com peso corporal médio de $555 \mathrm{~kg}$, dispostas em um delineamento em quadrado latino $4 \times 4$ duplo. No $18^{\circ}$ dia de cada período experimental, duas amostras de urina (manhã e tarde) foram coletadas manualmente de cada animal por meio de micção espontânea, utilizando-se frascos vazios e limpos. Uma alíquota de $5 \mathrm{~mL}$ de urina foi diluída em $45 \mathrm{~mL}$ de uma solução contendo ácido sulfúrico $(0,036 \mathrm{~N})$, mantendo o $\mathrm{pH}$ da amostra abaixo de 3 , com o objetivo de impedir a destruição bacteriana dos derivados de purinas e a precipitação de ácido úrico. As amostras identificadas foram armazenadas a $-20^{\circ} \mathrm{C}$ para que, ao final do experimento, fossem submetidas a análises laboratoriais. Ao final do experimento, as amostras de urina foram descongeladas e homogeneizadas para elaboração de uma amostra composta por vaca por período para quantificação dos derivados de purina $\mathrm{e}$ creatinina. A creatinina foi determinada com a utilização de kits comerciais $\left(\right.$ Labtest $\left.^{\circledR}\right)$, pelo método do ponto final, com uso de picrato e acidificante. As análises de ácido úrico também foram realizadas utilizando-se kits comerciais $\left(\right.$ Labtest $\left.^{\circledR}\right)$, pelo método do ponto final, com uso de uricase e peróxido de hidrogênio. A determinação das concentrações de alantoína seguiu a técnica descrita por Chen e Gomes (1992).

Os resultados foram interpretados estatisticamente, por meio de análise de contrastes, para determinar se as respostas obtidas comportavam-se com padrões lineares ou quadráticos (Statistical..., 1985).

\section{RESULTADOS E DISCUSSÃO}

Não foi observado efeito da suplementação lipídica com a adição de castanha de caju na dieta sobre o $\mathrm{pH}$ ruminal (Fig. 1). O valor médio de $\mathrm{pH}$ entre os tratamentos foi de 5,95. Os maiores valores de $\mathrm{pH}$ foram obtidos nos tempos 
próximos e imediatamente anteriores à alimentação da tarde e à da manhã. A partir do horário de fornecimento do alimento, à zero hora e às 12 horas, foi constatado que, após três horas, às três e às 15 horas, o pH atingiu menor valor, refletindo a ação fermentadora dos microrganismos do rúmen. Os valores de $\mathrm{pH}$ durante a primeira alimentação foram inferiores aos obtidos durante a segunda para os mesmos tempos após a alimentação. Tanto para o fornecimento das dietas à tarde como para o da manhã, o pH do rúmen iniciou a elevação de seus valores seis horas após a alimentação, às seis horas e às 18 horas, respectivamente. De acordo com Van Soest (1994), a faixa de pH para atividade normal das bactérias celulolíticas está situada entre 6,2 e 7,2, sendo ideal para o crescimento desses microrganismos o $\mathrm{pH}$ igual a 6,7. Desvios substancialmente acima ou abaixo deste valor são prejudiciais à atividade desse grupo de bactérias.

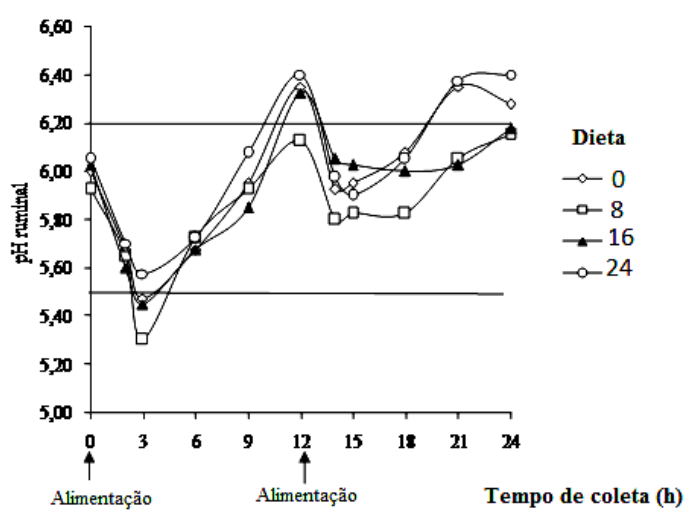

Figura 1. Potencial hidrogeniônico em função do tempo de coleta após a alimentação de vacas em lactação com diferentes proporções de castanha de caju na dieta.

A presença de alimentos, na formulação de dietas para vacas leiteiras que apresentem maior quantidade de nutrientes digestíveis, passíveis de sofrerem fermentação microbiana, é prática necessária para que se obtenha a produção de leite almejada, sendo que tais componentes podem originar produtos durante a fermentação que influenciem o $\mathrm{pH}$ do ambiente ruminal, possibilitando a permanência do $\mathrm{pH}$ abaixo de 6,2. Com exceção das adições de 8 e $16 \%$ de castanha de caju, às três horas, não foi observado $\mathrm{pH}$ abaixo do valor crítico de 5,5, o que poderia predispor os animais ao risco de acidose ruminal. Mudanças no $\mathrm{pH}$ ruminal de vacas que recebem
$6 \%$ de lipídeos na dieta não foram observadas por Vargas et al. (2002), semelhante aos dados observados na presente pesquisa. Harvatine e Allen (2006) também não observaram alteração no $\mathrm{pH}$ ruminal de vacas que receberam gordura insaturada, 7,8\% de ácidos graxos na dieta.

A concentração média de nitrogênio amoniacal $\left(\mathrm{N}-\mathrm{NH}_{3}\right)$ foi $12,70 \mathrm{mg} / 100 \mathrm{~mL}$ de líquido ruminal (Tab. 3). Todas as médias observadas foram superiores a 5mg/100mL, concentração estabelecida por Satter e Slyter (1974) como mínimo necessário para a adequada fermentação microbiana no rúmen. A concentração ruminal de amônia pode ser indicativo de fermentação de aminoácidos, elevado teor de proteína degradável no rúmen ou, ainda, reduzida quantidade de carboidratos não fibrosos no rúmen. Dessa forma, a ausência de alteração nos teores de N$\mathrm{NH}_{3}$ demonstra que o fornecimento de lipídeos insaturados, por meio da inclusão de castanha de caju na dieta, não promoveu efeito depressor sobre a população de bactérias Gram-positivas, fermentadoras obrigatórias de aminoácidos para suprir suas necessidades energéticas e proteicas (Vargas et al., 2002).

Foram observados picos de produção de amônia, aproximadamente, duas horas após a alimentação, 22,28; 22,28 e 20,18mg/100mL, após a alimentação da tarde, e 20,67; 13,12 e $15,35 \mathrm{mg} / 100 \mathrm{~mL}$, após o arraçoamento da manhã, respectivamente, para as dietas com $8 ; 16$ e $24 \%$ de castanha de caju no concentrado. A menor concentração de $\mathrm{N}_{-} \mathrm{NH}_{3}$ foi obtida nove horas após o arraçoamento, 9,20; 12,87 e $9,16 \mathrm{mg} / 100 \mathrm{~mL}$, após a alimentação da tarde, e 10,$40 ; 7,43$ e $5,82 \mathrm{mg} / 100 \mathrm{~mL}$, após o arraçoamento da manhã, respectivamente, para as dietas com 8; 16 e $24 \%$ de castanha de caju no concentrado.

Rabello et al. (1996) encontraram concentrações máximas de amônia uma hora e quarenta e sete minutos após a alimentação, com valores de 21,$4 ; 20,6 ; 19,9$ e $19,2 \mathrm{mg} / 100 \mathrm{~mL}$ de líquido ruminal, para a inclusão de $0 ; 15 ; 30$ e $45 \%$ de grão de soja, respectivamente. Segundo esses pesquisadores, o decréscimo na concentração de amônia no rúmen é o efeito mais consistente da suplementação com lipídeos, em vista da maior absorção de amônia em razão da menor alteração do $\mathrm{pH}$, resultando em aumento na eficiência microbiana. 
Tabela 3. Concentração de nitrogênio amoniacal $\left(\mathrm{N}-\mathrm{NH}_{3} \mathrm{mg} / 100 \mathrm{~mL}\right)$ no líquido ruminal de vacas em lactação com diferentes proporções de castanha de caju (CC) na dieta

\begin{tabular}{cccccc}
\hline \multirow{2}{*}{$\begin{array}{c}\text { Tempo } \\
\text { (horas) }\end{array}$} & 0 & 8 & 16 & 24 & Média \\
\cline { 2 - 6 } & 9,66 & 9,47 & 9,78 & 8,91 & 9,45 \\
2 & 16,83 & 22,28 & 22,28 & 20,18 & 20,39 \\
3 & 19,31 & 20,92 & 19,31 & 13,37 & 18,23 \\
6 & 12,87 & 10,89 & 10,52 & 10,15 & 11,11 \\
9 & 12,50 & 9,20 & 12,87 & 9,16 & 10,93 \\
12 & 11,76 & 13,74 & 9,16 & 9,41 & 11,02 \\
14 & 18,32 & 20,67 & 13,12 & 15,35 & 16,87 \\
15 & 14,11 & 16,71 & 11,76 & 12,63 & 13,80 \\
18 & 9,78 & 11,26 & 8,79 & 6,56 & 9,10 \\
21 & 10,15 & 10,40 & 7,43 & 5,82 & 8,45 \\
24 & 10,89 & 10,65 & 10,89 & 8,66 & 10,27 \\
Média & 13,29 & 14,20 & 12,36 & 10,93 & - \\
\hline
\end{tabular}

1 0: dieta sem CC; 8: dieta com 8\% de CC na porção concentrada; 16: dieta com 16\% de CC na porção concentrada; 24: dieta com $24 \%$ de CC na porção concentrada. Erro- padrão da média = 0,62; contrastes (valor de P): efeito linear $=0,75$; efeito quadrático $=0,99$.

As concentrações médias de acetato, propionato e butirato apresentaram padrão linear de resposta ( $\mathrm{P}=0,04$; Tab. 4). Grummer et al. (1993), ao avaliarem a suplementação lipídica com uso de $0 ; 1 ; 2$ e $3 \%$ de sebo na matéria seca da dieta, com teores respectivos de ácidos graxos de 5,5; 6,$3 ; 6,9$ e $7,6 \%$ nas dietas experimentais avaliadas, observaram aumento linear nas concentrações de ácidos graxos voláteis, coincidindo com os dados de $\mathrm{pH}$ encontrados.

Tabela 4. Concentrações de acetato, propionato e butirato (mmol/100mL) no líquido ruminal de vacas em lactação com diferentes proporções de castanha de caju (CC) na dieta

\begin{tabular}{|c|c|c|c|c|c|c|c|c|c|c|c|c|c|c|c|}
\hline \multirow{3}{*}{$\begin{array}{l}\text { Tempo } \\
\text { (horas) }\end{array}$} & \multicolumn{5}{|c|}{ Acetato $^{2}$} & \multicolumn{4}{|c|}{ Propionato $^{3}$} & \multicolumn{6}{|c|}{ Butirato $^{4}$} \\
\hline & \multicolumn{4}{|c|}{ Dieta $^{1}$} & \multirow{2}{*}{ Média } & \multicolumn{4}{|c|}{ Dieta $^{1}$} & \multirow{2}{*}{ Média } & \multicolumn{4}{|c|}{ Dieta $^{1}$} & \multirow{2}{*}{ Média } \\
\hline & 0 & 8 & 16 & 24 & & 0 & 8 & 16 & 24 & & 0 & 8 & 16 & 24 & \\
\hline 0 & 23,41 & 20,37 & 28,14 & 33,96 & 26,47 & 9,12 & 8,60 & 9,71 & 14,56 & 10,50 & 3,58 & 2,97 & 3,44 & 4,82 & 3,70 \\
\hline 2 & 32,94 & 34,60 & 30,88 & 41,76 & 35,05 & 12,05 & 11,57 & 11,16 & 17,52 & 13,08 & 5,77 & 5,23 & 4,38 & 6,20 & 5,40 \\
\hline 3 & 36,55 & 28,33 & 30,95 & 40,58 & 34,10 & 13,84 & 11,37 & 12,08 & 16,18 & 13,37 & 6,16 & 4,51 & 4,73 & 5,99 & 5,35 \\
\hline 6 & 35,92 & 21,80 & 34,84 & 60,27 & 38,21 & 14,76 & 9,83 & 13,36 & 26,22 & 16,04 & 4,85 & 3,36 & 4,87 & 7,93 & 5,25 \\
\hline 9 & 28,77 & 24,90 & 34,42 & 31,29 & 29,85 & 10,96 & 10,18 & 12,42 & 15,44 & 12,25 & 4,44 & 3,76 & 4,56 & 5,34 & 4,53 \\
\hline 12 & 21,77 & 22,43 & 27,15 & 26,25 & 24,40 & 8,74 & 9,74 & 12,59 & 10,19 & 10,32 & 2,87 & 3,29 & 5,05 & 4,37 & 3,90 \\
\hline 14 & 30,11 & 28,76 & 25,90 & 39,01 & 30,95 & 12,29 & 11,53 & 10,34 & 17,68 & 12,96 & 4,92 & 4,56 & 3,64 & 5,99 & 4,78 \\
\hline 15 & 36,47 & 30,81 & 26,28 & 33,92 & 31,87 & 15,50 & 11,25 & 12,26 & 11,61 & 12,66 & 5,35 & 4,64 & 4,07 & 3,78 & 4,46 \\
\hline 18 & 46,39 & 29,19 & 28,04 & 31,31 & 33,73 & 17,94 & 11,72 & 10,80 & 12,47 & 13,23 & 6,59 & 4,46 & 3,79 & 2,94 & 4,45 \\
\hline 21 & 40,35 & 23,95 & 33,98 & 49,58 & 36,97 & 15,30 & 10,15 & 12,05 & 13,01 & 12,63 & 6,09 & 3,30 & 3,92 & 5,61 & 4,73 \\
\hline 24 & 44,75 & 19,71 & 29,44 & 34,30 & 32,05 & 16,25 & 8,94 & 12,24 & 11,64 & 12,27 & 6,74 & 2,94 & 4,78 & 3,78 & 4,56 \\
\hline Média & 34,31 & 25,90 & 30,00 & 38,38 & - & 13,34 & 10,44 & 11,73 & 15,14 & - & 5,21 & 3,91 & 4,29 & 5,16 & - \\
\hline
\end{tabular}

${ }^{1} 0$ : dieta sem CC; 8: dieta com 8\% de CC na porção concentrada; 16 : dieta com $16 \%$ de CC na porção concentrada; $24:$ dieta com $24 \%$ de CC na porção concentrada. ${ }^{2}$ Erro-padrão da média $=2,55$; contrastes $($ valor de $\mathrm{P}$ ): efeito linear $=0,04$; efeito quadrático $=$ 0,18 . ${ }^{3}$ Erro-padrão da média $=0,99$; contrastes $\left(\right.$ valor de P): efeito linear $=0,08$; efeito quadrático $=0,31$. ${ }^{4}$ Erro-padrão da média $=$ 0,36 ; contrastes (valor de $\mathrm{P}$ ): efeito linear $=0,04$; efeito quadrático $=0,20$.

A relação acetato:propionato não foi alterada pela adição de castanha de caju à dieta (Fig. 2). Vargas et al. (2002), ao avaliarem dietas com $6 \%$ de ácidos graxos oriundos do óleo de soja, observaram decréscimo na relação acetato:propionato - de 3,09 para 2,93 -, sugerindo que o fornecimento de lipídeos insaturados inibiu as bactérias ruminais Gram- positivas e estimularam as produtoras de propionato.

Reduções no consumo de matéria seca, na porcentagem de gordura no leite e na digestão da fibra no rúmen são indicadores de alteração na fermentação ruminal, fato que não ocorreu na presente pesquisa. A taxa na qual os ácidos graxos são liberados dos alimentos e expostos 
aos microrganismos ruminais determina se a fermentação é influenciada. Se a capacidade dos microrganismos em biohidrogenar os lipídeos for saturada, os ácidos graxos insaturados acumulados poderão interferir na fermentação (Nutrient..., 2001). A maioria das pesquisas sobre o uso de lipídeos saturados e insaturados para vacas em lactação tem demonstrado pequenos efeitos sobre os parâmetros ruminais (Vargas et al., 2002).

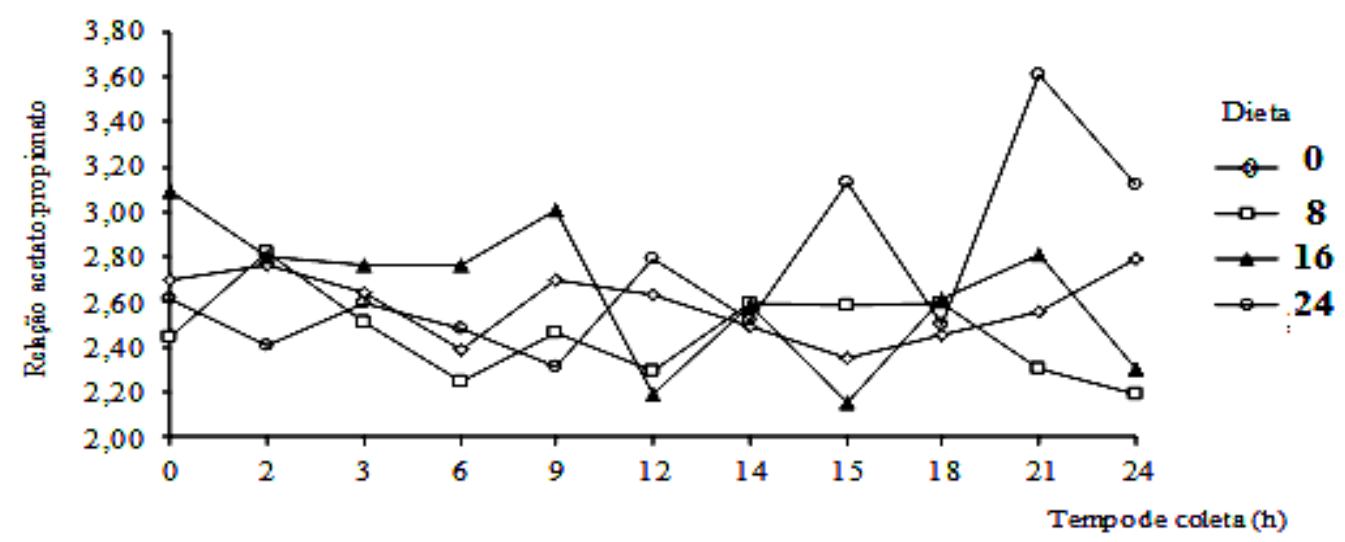

Figura 2. Relação acetato:propionato no líquido ruminal em função do tempo após a alimentação de vacas em lactação com diferentes proporções de castanha de caju na dieta

As excreções de alantoína, ácido úrico e creatinina na urina não foram influenciadas com a inclusão de castanha de caju ao concentrado de vacas em lactação (Tab. 5). A excreção urinária de derivados de purinas pelos ruminantes pode ser utilizada para estimar o fluxo intestinal de proteína microbiana (Chen e Gomes, 1992). O referido método considera que o fluxo duodenal de ácido nucleico é predominantemente de origem microbiana e, após a digestão intestinal das bases purinas (adenina e guanina) microbianas, estas são catabolizadas e excretadas proporcionalmente à quantidade produzida.

Tabela 5. Concentrações de alantoína, ácido úrico e creatinina $(\mathrm{g} / \mathrm{L})$ e relação alantoína/creatinina de vacas em lactação com diferentes proporções de castanha de caju (CC) na dieta

\begin{tabular}{|c|c|c|c|c|c|c|c|}
\hline \multirow{2}{*}{ Variável } & \multicolumn{4}{|c|}{ Dieta $^{1}$} & \multirow{2}{*}{$\mathrm{EPM}^{2}$} & \multicolumn{2}{|c|}{ Contraste $^{3}$} \\
\hline & 0 & 8 & 16 & 24 & & $\mathrm{~L}$ & $\mathrm{Q}$ \\
\hline Alantoína & 4,41 & 3,96 & 3,85 & 3,96 & 0,14 & 0,19 & 0,30 \\
\hline Ácido úrico & 0,50 & 0,44 & 0,37 & 0,38 & 0,02 & 0,16 & 0,40 \\
\hline Creatinina & 1,04 & 1,14 & 0,96 & 0,95 & 0,04 & 0,75 & 0,47 \\
\hline Alantoína:creatinina & 4,77 & 3,58 & 4,03 & 4,26 & 0,18 & 0,05 & 0,07 \\
\hline
\end{tabular}

${ }^{1}$ 0: dieta sem CC; 8: Dieta com 8\% de CC na porção concentrada; 16: dieta com 16\% de CC na porção concentrada; 24: dieta com $24 \%$ de CC na porção concentrada. ${ }^{2} \mathrm{EPM}$ : erro-padrão da média. ${ }^{3}$ Contrastes (valor de P): $\mathrm{L}=$ efeito linear; $\mathrm{Q}=$ efeito quadrático.

A relação alantoína:creatinina variou entre 3,58 e 4,77, contudo apresentou somente tendência linear de resposta aos tratamentos utilizados $(\mathrm{P}=0,05)$. A excreção de creatinina é presumidamente proporcional à perda de massa corporal, fato não observado na presente pesquisa. Desse modo, a elevada relação alantoína:creatinina reflete a excreção de alantoína, a qual sugere adequado crescimento microbiano para as dietas sem inclusão de castanha de caju e para todas aquelas em que o coproduto foi utilizado. Reis et al. (2001) observaram valores de 1,75 e 2,97 na relação alantoína:creatinina ao utilizarem, respectivamente, forragem fresca sem suplementação e forragem fresca mais $10 \mathrm{~kg}$ de concentrado com elevada proporção de milho com alta umidade na sua composição. Possivelmente, a inclusão de castanha de caju à dieta não interferiu no crescimento dos 
microrganismos do rúmen e, consequentemente, no aporte de proteína microbiana para a glândula mamária.

\section{CONCLUSÕES}

A inclusão do coproduto da castanha de caju não influencia os parâmetros de fermentação ruminal nem as concentrações de derivados de purinas, podendo ser considerado como substituto dos ingredientes convencionais milho e farelo de soja nos concentrados para vacas leiteiras em lactação.

\section{REFERÊNCIAS}

CHEN, X.B.; GOMES, M.J. Estimation of microbial protein supply to sheep and cattle based on urinary excretion of purine derivativesan overview of technical details. Aberdeen: Rowett Research Institute, 1992. 21p.

GRUMMER, R.R.; LUCK, M.L.; BARMORE, J.A. Rumen fermentation and lactation performance of cows fed roasted soybeans and tallow. J. Dairy Sci., v.76, p.2674-2681, 1993.

HARVATINE, K.J.; ALLEN, M.S. Effects of fatty acid supplements on feed intake, and feeding and chewing behavior of lactating dairy cows. J. Dairy Sci., v.89, p.1104-1112, 2006.

MAIA, F.J.; BRANCO, A.F.; MOURO, G.F. et al. Inclusão de fontes de óleo na dieta de cabras em lactação: produção, composição e perfil dos ácidos graxos do leite. Rev. Bras. Zootec., v.35, p.1504-1513, 2006.

NUTRIENT requirements of dairy cattle. 7nd. ed. Washington, DC: National Academy, 2001. $381 \mathrm{p}$.

OFFICIAL methods of analysis. 16nd. ed. Washington, DC: AOAC, 1995. 1094p.

OLIVEIRA, R.L.; BAGALDO, A.R.; LADEIRA, M.M. et al. Fontes de lipídeos na dieta de búfalas lactantes: consumo, digestibilidade e N-ureico plasmático. R. Bras. Zootec., v.38, p.553-559, 2009.
PIMENTEL, P.G.; MOURA, A.A.A.N.; NEIVA, J.N.M. et al. Consumo, produção de leite e estresse térmico em vacas da raça Pardo-Suíça alimentadas com castanha de caju. Arq. Bras. Med. Vet. Zootec., v.59, p.1523-1530, 2007.

RABELLO, T.G.; VALADARES FILHO, S.C.; SILVA, J.F.C. et al. Grão de soja moído na alimentação de vacas em lactação. III. Eficiência microbiana, amônia e pH. Rev. Bras. Zootec., v.25, p.270-280, 1996.

REIS, R.B.; SAN EMETERIO, F.; COMBS, D.K. et al. Cost effects of corn particle size and source on performance of lactating cows fed direct-cut grass-legume forage. J. Dairy Sci., v.84, p.429-441, 2001.

SATTER, L.D.; SLYTER, L.L. Effect of ammonia concentration on rumen microbial protein production in vitro. Br. J. Nutr., v.32, p.199-205, 1974.

SNIFFEN, C.J.; O'CONNOR, J.D.; VAN SOEST, P.J. et al. A net carbohydrate and protein system for evaluating cattle diets. II Carbohydrate and protein availability. J. Anim. Sci.,v.70, p.3562-3577, 1992.

STATISTICAL Analysis System - SAS. SAS user's guide. Cary: 1999. v.8, 295p. 1985.

VAN SOEST, P.J. Nutritional ecology of the ruminant. Ithaca: Cornell, 1994. 476p.

VAN SOEST, P.J.; ROBERTSON, J.B.; LEWIS, B.A. Methods for dietary fiber, neutral detergent fiber and nonstarch polysaccharides in relation to animal nutrition. J. Dairy Sci., v.74, p.35833597, 1991.

VARGAS, L.H.; LANA, R.P.; JHAM, G.N. et al. Adição de lipídios na ração de vacas leiteiras: parâmetros fementativos ruminais, produção e composição do leite. Rev. Bras. Zootec., v.31, supl. 1, p.522-529, 2002. 